\title{
EL PENSAMIENTO \\ PEDAGÓGICO DE PLATÓN
}

María Guadalupe García Casanova

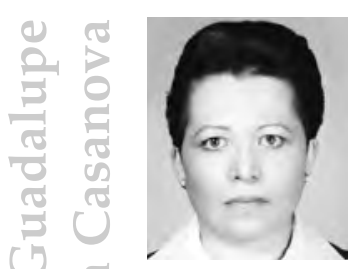

Doctora en Pedagogía, Facultad de Filosofía y Letras, UNAM. Profesora Asociada «C» de Tiempo Completo. Docente de la Licenciatura y el Posgrado en Pedagogía, Facultad de Filosofía y Letras, UNAM. Secretaria Académica del Seminario de Pedagogía Universitaria, Facultad de Filosofía y Letras, UNAM. Profesora investigadora. Docente del Posgrado en Enseñanza Superior, Centro de Investigación y Docencia en Humanidades del Estado de Morelos. Coordinadora del Posgrado en Enseñanza Superior, Centro de Investigación y Docencia en Humanidades del Estado de Morelos.

Correo electrónico: [mggarciacasanova@yahoo.com.mx].

\section{DATOS BIOGRÁFICOS Y CONTEXTUALES}

Atenas se constituyó en prototipo de educación, dejó de ser esencialmente militar y mostró ante todo un carácter civil, a diferencia de la educación proporcionada en Esparta. La educación aristocrática se convirtió - aunque con la desaprobación de esa clase social- en modelo para la educación de todo joven griego libre, lo que llevó a la creación y desarrollo de la escuela, al parecer en el último tercio del siglo VII a.C. ${ }^{1}$.

El pensamiento filosófico griego del siglo $\mathrm{V}$ a.C. había agotado las discusiones filosóficas del siglo anterior en torno al problema cosmológico

\footnotetext{
${ }^{1}$ Henri Irénée Marrou, Historia de la educación en la antigüedad, p. 73.
} 
(esto es, la búsqueda del origen y la naturaleza de las cosas), resaltando los postulados de Heráclito, Empédocles, Leucipo, Demócrito, Anaxágoras y Pitágoras. El siglo V, del que ahora nos ocuparemos, fue testigo de las discusiones filosóficas referentes a la naturaleza del hombre, y es precisamente en torno a estas discusiones en las que Platón plasmó una profunda huella.

Para hablar del contexto cultural y educativo de Grecia, es necesario distinguir la educación espartana de la ateniense, debido a que la primera, un poco más militar, descuidaba un tanto la formación literaria para fortalecer la formación del cuerpo y la cultura cívica. En cambio, Atenas se reconocía como un estado de cultura, en el que la formación literaria — que alimentaba el espíritu-, poseía la mayor preeminencia educativa. Sin embargo, no podemos afirmar que la educación haya adquirido en este siglo su máxima consolidación; para ello deberá esperar el período helenístico.

El contenido de la educación en esta época — supuesto el dominio de la lectura, la escritura y la aritmética-, se conformó principalmente mediante dos elementos: la gimnasia y la música. La primera como cultivo y preparación del cuerpo para el combate y la competencia; y la segunda, como es bien sabido, por el estudio de las musas, además de la cultura musical propiamente dicha.

Platón - cuyo nombre verdadero era Aristocles, como su abuelonació el 27 de mayo de 427 y murió en el 347 antes de nuestra era, y fue hijo de Aristón y Perictione, procedentes ambos de grandes linajes aristocráticos ${ }^{2}$. Su infancia transcurrió durante los años de la Guerra del Peloponeso. En ella recibió la educación habitual de los atenienses que él mismo describe en su diálogo Protágoras y cumplió sus años de servicio militar como ephebo. A partir del año 407 fue discípulo de Sócrates, discipulado que duraría veinte años. Durante su juventud tuvo lugar el episodio denominado la Tiranía de los Treinta. La trágica muerte de

2 Entrada Plato, The Americana. A Universal Reference Library. 
Sócrates lo afectó notablemente, acontecimiento que lo llevó a viajar al Norte de África, en especial a Egipto, Sicilia e Italia Meridional, en el período comprendido entre el 399 y el 389. Es en Sicilia donde al parecer fue seducido por los estudios pitagóricos ${ }^{3}$.

En uno de sus viajes a esta ciudad italiana trabó amistad con Dion, cuñado del tirano Dionisio I, gobernante de Siracusa. Dion lo condujo con el tirano y ahí Platón, influido por su ideal de república justa, se sintió en libertad de criticar el gobierno de Dionisio, quien se ofendió por las abiertas críticas del filósofo. Ante tal atrevimiento, se le envió con el embajador lacedemonio para ser vendido como esclavo. Para su fortuna, lo reconoció un socrático, llamado Anniceris, y fue rescatado pagando el precio convenido ${ }^{4}$.

En el 389, después de su liberación, regresó a Atenas y enseñó en el gymnasion, situado en el bosque dedicado al héroe primitivo Academo, motivo por el cual su escuela fue popularmente conocida como la Academia ${ }^{5}$.

La forma como se desarrollaban las clases de la Academia es, sin duda, una cuestión muy discutida y de la que sólo puede conjeturarse, debido a que nuestro autor en sus escritos arremete contra las lecciones formales y contra la costumbre de consignarlas por escrito, de manera que únicamente ha llegado hasta nosotros una única lección en ese recinto: la que trata del «Bien» ${ }^{6}$. Criticó, asimismo, los manuales de instrucción y en general toda consignación por escrito de las lecciones, cuestión que encontramos bellamente explicada a través del mito relatado en el diálogo Fedro $^{7}$, donde el dios egipcio Theuth —inventor del cálculo, la geometría

James Bowen, Historia de la educación occidental. El mundo antiguo. 2000 a.C.-1050 d.C. Oriente próximo y Mediterráneo, tomo I, p. 147.

4 The Americana. A Universal Reference Library.

Bowen, op. cit., p. 147.

Ibidem, p. 148.

7 Platón, «Fedro», Diálogos. [Fedón, Banquete, Fedro], tomo III, Biblioteca Clásica Gredos, núm. 93, 274c-275b. 
y, por supuesto, las letras - llevó el invento de las letras al rey egipcio Tamus, promocionándolo como el fármaco de la memoria y la sabiduría. Ante ello, replicó Tamus que el uso de las letras los haría parecer que poseían muchos conocimientos cuando, en la mayoría de los casos, eran totalmente ignorantes y difíciles, y acabarían por convertirse en sabios aparentes en lugar de sabios de verdad.

De acuerdo con Larroyo, el período en el que transcurrió la vida de Platón se caracterizó por ser crítico-constructivo, destacando los escritos históricos de Herodoto, inundados de narraciones pintorescas y delicadas. Fue el momento en el que Tucídides escribió La Guerra del Peloponeso que narraba los hechos históricos, buscando sus causas y subrayando la importancia de las instituciones sociales. En ese momento se leían con asiduidad las tragedias de Eurípides y los escritos retóricos que mostraban la solemnidad de Esquilo y la perfección ática de Sófocles. En esas circunstancias, Platón convirtió la prosa en un dúctil instrumento para plasmar sus ideas políticas y pedagógicas, ideas que hicieron época en la historia del pensamiento humano ${ }^{8}$.

\section{EL CORPUS PLATÓNICO}

La obra de nuestro autor es enorme. Sus estudiosos la dividen en cuatro épocas: a) la primera, denominada «de juventud», abarca los escritos elaborados entre el 393 y el 389, donde se incluyen Apología, Ion, Critón, Protágoras, Laques, Trasímaco, Lisis, Cármides y Eutifrón; b) en la segunda, «de transición» (del 388 al 395), se encuentran Gorgias, Menón, Eutidemo, Hipias Menor, Crátilo, Hipias Mayor y Menéxeno; c) en el período que sus estudiosos consideran que Platón escribió en su mejor momento, lo llaman «época de madurez» (385-370) y ubican escritos como Banquete, Fedón, República y Fedro; d) por último, la época «de vejez» que considera los escritos del 369 al 347, la cual incluye Teeteto, Parménides, Sofista, Político, Felebo, Timeo, Críticas, Leyes y Epinomis ${ }^{9}$.

Francisco Larroyo, Historia general de la pedagogía, p. 155.

Ver el estudio preliminar en Platón, Diálogos. [Apología, Critón, Eutifrón, Ión, Lisis, Cármenides, Hipias Menor, Hipias Mayor, Laques, Protágoras], Biblioteca Clásica Gredos, núm 37. 


\section{POSTULADOS FILOSÓFICOS DEL PENSAMIENTO PLATÓNICO}

El pensamiento filosófico y el pedagógico de Platón se encuentran íntimamente ligados. Para comentar su pensamiento filosófico, en primera instancia es necesario mencionar su teoría del conocimiento. En el diálogo Menón, las ideas plasmadas implican una teoría gnoseológica que, por supuesto, repercute en la teoría del aprendizaje y la enseñanza. En dicho diálogo, Platón sostiene que el alma es inmortal, que reencarna muchas veces $y$, por tanto, que ha visto todas las cosas aquí [en el mundo] y en Hades, de manera que no existe nada que no haya aprendido. Para demostrar de «manera práctica» que no se aprende — esto es, que el conocimiento se encuentra en el alma-, Platón pide a Menón llame a uno de sus esclavos, Anito, a quien le solicita la resolución de un problema geométrico complicado. Mediante la mayéutica, al preguntar, dirigiendo al esclavo a la respuesta correcta, Platón demuestra que un esclavo, sin instrucción geométrica alguna, ya tenía la respuesta en su alma y sólo necesitaba recordarla ${ }^{10}$. Platón considera que este proceso se llama reminiscencia. Así «[...] el buscar [recordar un conocimiento] y el aprender son enteramente reminiscencia» ${ }^{11}$, pues «El tomar un conocimiento de sí mismo ¿no es acordarse?» ${ }^{12}$. De acuerdo con Ute Schmidt, esta forma de pensar está en la línea de Leibniz y Kant, para quienes el alma humana no es una tábula rasa, sino que dispone de un saber latente ${ }^{13}$.

En el Fedón ${ }^{14}$, nuestro autor explica que el conocimiento no deriva de las impresiones sensoriales, sino que subyace en nuestras memorias mediante formas o moldes de ideas, de realidades que conocía el alma antes de llegar a esta vida, al descender a este mundo inferior.

10 Platón, Menón, 81b - 86b.

11 Ibidem, 81d.

12 Ibidem, 85d.

${ }_{13}$ Ver Introducción de Ute Schmidt en el Menón.

14 Platón, «Fedón», op. cit., 75b-76a. 
La manera como el conocimiento queda impreso en el alma también se encuentra expuesta en otro de sus diálogos, Gorgias, donde elabora una analogía entre las cicatrices del cuerpo y las del alma:

Entonces, lo mismo me parece válido también referente al alma, Calicles: todo es manifiesto en ella, una vez despojada del cuerpo, tanto lo de su naturaleza, como las experiencias que por el afán de cada una de las cosas que el hombre tenía en su alma [...] mostrando las huellas que cada acción impregnó en su alma ${ }^{15}$.

Ahora bien, para redondear la postura platónica sobre el conocimiento es necesario remitirse al libro séptimo de la República ${ }^{16}$ donde, por medio de un mito gnoseológico, nos presenta lo que opina del defectuoso papel de los sentidos del hombre en la adquisición del conocimiento. La alegoría de la caverna, nos lleva a imaginar a un hombre atado frente a la pared de una oscura cueva. Atrás suyo alumbra una fogata y las personas pueden transitar entre él y la fogata, de manera que las imágenes reflejadas en la pared de la cueva, por efecto del fuego, le muestran impresiones imperfectas debido a lo rocoso de la pared. Así las cosas, si pasa una mujer con un cántaro, el hombre percibe la silueta y no puede percatarse de que el cántaro no es parte de ella. Incluso, en caso de que él pueda salir de la cueva, la luz lo deslumbraría a tal grado que tampoco podría percibir la verdad. Como observamos, esa luz que lo deslumbra es metafóricamente el conocimiento, de manera que haber pasado tanto tiempo en la oscuridad de la ignorancia le impedirá, cuando él sale, reconocer la verdad del conocimiento.

Es así como Platón despoja a los sentidos de un papel relevante en la adquisición del conocimiento, de manera que le tocará a su discípulo Aristóteles rescatar el honroso papel de los sentidos, que será retomado muchos siglos después principalmente por Descartes, Bacon y Locke.

${ }_{15}$ Platón, Gorgias, 524d y 525a. [Los corchetes son míos].

${ }_{16}$ Platón, Diálogos. [República], tomo IV, Biblioteca Clásica Gredos, núm. 94, principio del libro VII. 


\section{ELEMENTOS CARACTERÍSTICOS DE SU PENSAMIENTO PEDAGÓGICO}

El pensamiento pedagógico del autor que nos ocupa es de enorme relevancia, sus ideas en cuanto a la enseñanza se plasman en Protágoras y en Menón. El tema central de la obra temprana Protágoras es la enseñabilidad de la virtud; para determinar si la virtud puede ser enseñada, se discute su naturaleza, lo que lleva a la construcción de la definición de la virtud, y si existe una sola o son diversas virtudes, aspectos relacionados con la educación. Se observa, entonces, que el término virtud no es unívoco en este diálogo, pueden detectarse varias acepciones, entre las que es importante mencionar ${ }^{17}$ :

1. La virtud concebida como la forma de actuar socialmente requerida, debido a que desde el nacimiento el hombre se ve influenciado por acciones socializadoras de su medio.

2. La virtud como la habilidad [«competencia», dirían ahora] para administrar los bienes o asuntos propios o públicos.

3. La virtud como la capacidad excepcional de un hombre de estado.

De tales acepciones de virtud, se desprende que ésta es un elemento necesario para vivir en sociedad, es decir es una virtud política.

Pero ¿cómo se adquiere la virtud? ¿La virtud se puede enseñar? Para intentar encontrar las respuestas habremos de retomar el Menón, texto en el que Platón considera que el conocimiento ya está en el alma, es decir, es previo e independiente de toda experiencia. Así las cosas, aprender es acordarse de lo que ya se sabe y, por tanto, enseñar es sacar a la luz el conocimiento del alumno mediante la mayéutica, este proceso es activo de parte de ambos participantes del proceso educativo. Sin embargo, el Menón no plantea la respuesta, que deberemos encontrar en la República. 
La República, un texto que bien puede llamarse utópico, es la obra en que Platón plasma su idea de un estado perfecto, donde sus habitantes deberán ser lo más perfectos posibles. Para ello, deja en manos de los filósofos el gobierno de esta polis justa. Toda la república perfecta está sustentada en la educación de los ciudadanos, de manera que cumplan bien la función que les toca realizar. Esta obra consta de diez libros y los aspectos educativos se desarrollan prioritariamente en los libros dos, tres y cuatro.

El estado perfecto está dividido en tres estamentos. Empezaré por el primero, el de los artesanos(as) y el de los campesinos(as), cuya función es suministrar el sostén económico de toda la comunidad. Ahora bien, debido a que son el estamento más factible de caer en la concupiscencia, la virtud que debe fomentar la educación es la de la templanza, para que sean capaces de dominarse en cuanto a la comida, bebida y los excesos en las relaciones sexuales. Para Platón, este estamento no requiere de educación ya que no la especifica, como tampoco si se somete a la enseñanza de su oficio.

El segundo estamento, es el de los guerreros(as), su función es la de defender a la ciudad en caso de guerra, y administrar y ejecutar las órdenes del primer estamento en tiempo de paz. Deben ser valientes y moderados, lo que implica que deben poseer además de la templanza, la valentía, de manera que no teman a la muerte, deben estar serenos para suprimir las emociones fuertes, no caer en la concupiscencia, ser fraternales con sus conciudadanos y honrar a los dioses. Los preceptos de su educación, son retomados por Platón de su realidad, es decir, la gimnasia y la música. La primera, para el fortalecimiento del cuerpo, y la segunda, para el del alma, en donde la música está constituida, además del canto, la danza y el aprender a tocar un instrumento musical, por el estudio de las «musas», que fortalecen el ámbito de la educación intelectual, moral, religiosa y artística.

La educación del niño(a) que va a ser guerrero(a) empieza por la educación «musical». Se inicia en los más pequeños con la lectura de las fábulas, que deben servir como modelos de comportamiento, pues deberán tratar de dioses y héroes en una versión censurada; después, a los más 
grandes se les introduce a la literatura mediante la lectura de tragedias y comedias seleccionadas, cuyo propósito es prioritariamente una enseñanza moral, y su educación finaliza con una enseñanza musical, en su sentido moderno, donde está incluida la enseñanza de la danza. El papel educativo de la enseñanza musical tiene el propósito de producir moderación, de tal manera que son evitados los ritmos que favorezcan la concupiscencia y la embriaguez. Por cuanto toca a la educación del cuerpo, se inicia a muy temprana edad con el propósito de mantener la fortaleza y la salud del cuerpo, que conlleva a la salud del alma.

Los guerreros del segundo estamento conviven en comunidad con los del primero, no hay entre ellos propiedad privada ni matrimonio privado. Las mujeres y los hijos son comunes, para que se fomente un sentimiento de unidad. Se prescribe una edad específica para procrear. Es interesante observar que nuestro filósofo establece un principio de eugenesia, pues sólo los hombres más destacados deben unirse con las mujeres más destacadas para procrear, con la finalidad de reproducir en ellos las características de los padres.

De los mejores guerreros(as) se eligen los gobernantes, quienes conforman el primer estamento. Su educación, dirigida hacia la filosofía, requiere de mucho esfuerzo y tiempo. A los filósofos reyes corresponde, además de la templanza y la valentía - virtudes correspondientes a los otros dos estamentos-, la virtud de la sabiduría, y por tanto, gobiernan para el bien de los gobernados. El gobernante perfecto debe tener las siguientes cualidades:

- ¿Has de censurar entonces a una ocupación [la de los gobernantes] que no se puede practicar como es debido si no se está por naturaleza dotado de memoria, facilidad para aprender, grandeza de espíritu y de gracia y no se es amigo y congénere de la verdad, de la justicia, de la valentía y de la moderación?

- No, ni Momo censuraría algo por el estilo.

— ¿Y no es sólo a estos hombres, una vez perfeccionados por la educación y por la edad, que encomendarás el Estado? ${ }^{18}$.

${ }_{18}$ Platón, República, 487a-b. 
El gobernante perfecto inicia su educación como un guerrero, convive en la comunidad con ese estamento y no tiene propiedad alguna, cuestión que se consolida con la prohibición de tocar oro y plata. Sin embargo su educación difiere del guerrero(a) porque le dedicará más tiempo, constará en total de cincuenta años.

En dicha educación se profundiza el estudio de la aritmética, el cálculo, la geometría, la astronomía y la dialéctica, en ese orden, pues las primeras constituyen los estudios preparatorios para llegar a la reina de las ciencias, la dialéctica, que posibilitará, por medio del estudio constante, llegar a la «Idea del Bien».

Es comprensible observar que, para nuestro autor, el gobierno de su estado perfecto deba estar en manos de filósofos, cuestión que responde a dos razones, una de ellas es que en el siglo $V$ de Platón, lo que denominamos enseñanza superior se realizaba en las sectas filosóficas o bien a través de la enseñanza de los sofistas — que Platón desacredita- y la otra razón es, evidentemente, que él era filósofo.

Las Leyes, su última obra, es su trabajo más largo, desarrollado en doce libros, y tiene el propósito de diseñar una propuesta de legislación pormenorizada que gobierne una imaginaria ciudad ubicada en Creta, a la cual denomina «Magnesia», la cual nos presenta otra posibilidad de estado distinta a la de la República. Magnesia está lejos del mar, su economía se sustenta en la agricultura, donde están restringidas la importación y la exportación. A semejanza de la República, no se debe poseer oro ni plata; las transacciones comerciales se realizan mediante una moneda que no tiene valor fuera de la ciudad.

A diferencia de la República, en Magnesia gobierna una legislación, a la cual deben sujetarse todos los miembros de la comunidad. Dicho conjunto de normas debe procurar que los habitantes sean felices y amigos entre sí.

Todo el territorio de Magnesia se divide en 5,040 lotes correspondientes a cada familia en igualdad de condiciones. A diferencia de la República, desaparece la propiedad privada. Sucede lo mismo con la familia: regresa a 
la idea del matrimonio e hijos privados. Se sugiere el control de la natalidad, pues sólo uno de los hijos heredará el lote. El matrimonio es estrictamente monogámico y se espera la fidelidad entre ellos. En el ámbito de la procreación, no existe la planeación genética; los individuos deciden por sí mismos la adecuada elección de la mujer, en bien de los hijos (para que éstos sean mejores y más bellos); no obstante, el divorcio está permitido.

Todos los ciudadanos se dedican a la agricultura — unos a gozar de los beneficios, y otros, los esclavos, a las labores manuales de la agricultura-, ninguno de ellos aprende una labor artesanal o profesión, debido a que todas las demás ocupaciones las desarrollan extranjeros asalariados (como la labor de los docentes).

Aunque se supone una riqueza equivalente de todos los ciudadanos — por una habilidad no explicada por nuestro autor-, algunos serán más ricos que otros. De manera que, en relación a su riqueza, existirán cuatro clases de propiedad: simple, doble, triple o cuádruple, y en función de la clase a la que se pertenezca se asignarán los impuestos y, por supuesto, los cargos.

Las leyes regulan la vida de todo ciudadano, desde la cuna hasta la muerte. Se reglamentan el matrimonio, la procreación, la educación, los castigos a la criminalidad, los mercados, los juegos de los niños, lo que se lee en las escuelas y sobre todo las fiestas religiosas.

En cuanto a los órganos administradores de las leyes, existen cuatro. Sus miembros son elegidos a través de un sistema de votación, obligada a las dos clases de mayor riqueza, pero no a las dos clases menos ricas.

Un consejo nocturno vigila el cumplimiento de las leyes. Consta de veintidós miembros. Sólo él está facultado para la modificación de las leyes. Funge con las funciones de los poderes legislativo y judicial actuales. En las Leyes, dios es la medida de todas las cosas; los dioses justifican la ley, así este estado podría considerarse como teocrático. En el estado de las Leyes rige la religión olímpica politeísta —aunque en ocasiones 
Platón parece monoteísta-. El ateísmo y las herejías son castigados excesivamente; incluso, se insta a los ciudadanos a la delación de estos delitos. Existe una prisión correccional, de cinco años, para que los ateos confesos sean liberados de su ateísmo. Una vez pasado ese tiempo, si no cambian, serán asesinados. El culto tiene un papel importante en este estado. Diariamente debe oficiarse al menos una festividad religiosa. Los ritos, cantos y danzas están completamente reglamentados. Sólo se permiten los cultos oficiales.

Aunque el filósofo le dedica mucha atención a la educación, la concibe como la conducción de los niños hacia los principios y las doctrinas que la ley establece como los ortodoxos ${ }^{19}$; debe lograrse en ellos, el deseo de ser ciudadanos capaces de gobernar y ser gobernados, y conformar cuerpo y alma de la manera más bella y mejor posible ${ }^{20}$.

Todos reciben la misma educación, que es responsabilidad del estado. Existe una persona dedicada a vigilar la educación, quien ostenta un cargo importante que requiere de una persona mayor de cincuenta años y con experiencia como padre de familia, para que tenga práctica en educar niños. La educación inicia desde la gestación. La mujer embarazada debe rehuir las emociones fuertes y realizar ejercicio moderado, caminando. Igualmente se evitarán en el recién nacido los excesos de alegría y dolor para propiciar el dominio de sí mismo. En esta obra, Platón considera que la virtud se inculca como un hábito, esto es, puede ser adquirida por todos.

Entre los tres y seis años- vigilados por mujeres que ostentan un cargo menor-, niños y niñas juegan juntos. Se separan al cumplir los seis años y ambos sexos, cada uno por su lado, inician un entrenamiento físico: aprenderán a montar caballo, usar el arco, bailar y se propiciará que sean ambidiestros. Esta educación inicial concluirá a los diez años, que es cuando se llevará a cabo la instrucción intelectual: aprenderán a leer, escribir y contar, así como los elementos rudimentarios de

${ }_{19}$ Platón, Leyes, 658d.

${ }^{20}$ Ibidem, 788c. 
astronomía para la comprensión del calendario. A los catorce años se les enseña a tocar la lira. Toda la educación se realiza en la escuela, a cargo de maestros extranjeros. Se plantea un estudio más profundo de matemáticas y astronomía, pero no existe la educación superior, que se supone requieren los miembros del consejo nocturno.

La lectura de las Leyes muestra un estado totalitario: se prohíbe salir al extranjero, la moneda no tiene valor fuera de Magnesia, se favorece la vigilancia y delación mutuas -incluso de conductas sospechosas- y asombra la facilidad con que se sacrifica la vida humana.

\section{UTOPÍA Y ANTI-UTOPÍA EN EL PENSAMIENTO PEDAGÓGICO PLATÓNICO}

Al leer la República y las Leyes, observamos el diseño de «estados» muy distintos. Ello nos muestran un cambio en el autor; de joven, inicia escribiendo con una opinión optimista acerca del hombre y de la mujer y, ya viejo, termina descorazonado del género humano. Aunque algunos las consideren dos utopías, a mi juicio, la primera sí puede ser calificada como utopía, mientras la segunda me parece más una anti-utopía. Observemos sus características:

\section{La República:}

- Se sustenta en una sociedad dividida en estamentos en función de habilidades y educación. La mujer y el hombre son iguales; pueden realizar las mismas funciones, desde labores de agricultura hasta las de gobernante.

- La educación desarrolla todas las capacidades del individuo; intenta la formación integral y completa a que puede aspirar un ser humano, tomando en cuenta el logro de la Kalokagathía que constituye el ideal de la Paideia griega de la educación ateniense. En su nivel final, se forma a un hombre o una mujer cultos, quienes durante cincuenta años han estudiado a profundidad todas las áreas del saber humano, cultivando las siete artes liberales: gramática, dialéctica, retórica, aritmética, geometría, astronomía y música. La «música» culmina majestuosamente la formación del 
individuo, contribuyendo también a conformar el carácter (el ethos), con ayuda de las musas, hijas de Mnemosine ${ }^{21}$.

- El gobierno está a cargo un filósofo, quien a manera de buen pastor, decide los destinos del estado, buscando la justicia, el bien común y la felicidad de los individuos, de forma que se puede prescindir de las leyes.

- Intenta resolver los problemas observados en la sociedad ateniense en la que vive mediante la abolición de la propiedad privada, el matrimonio privado y los hijos propios.

- Parece no existir la esclavitud. El tercer estamento es el dedicado a la agricultura y las artesanías.

- Existe una división del trabajo sustentada en las habilidades y la educación: cada quien realiza bien lo que le toca hacer, es lo que da muestra de poseer la virtud.

- Si bien no existe el voto para la elección de sus gobernantes, parece existir la aceptación del pueblo ante la selección del más apto, educado y virtuoso.

\section{Las Leyes:}

- Aunque la educación inicia antes que en la República -antes de nacer-, el bajo nivel de educación de los ciudadanos «magnetos» hace necesaria la existencia de un estado sometido a leyes, y sólo algunos de ellos tomarán cursos más avanzados, pero en general, la mayoría de la población será poco escolarizada.

- La escrupulosa vigilancia de la observancia de las leyes parece mostrar un estado totalitario: los castigos son severos, se fomenta la delación y existe una gran facilidad para sacrificar la vida humana.

- Platón otorga más importancia a los fines del estado que a los del ciudadano, ya que el hombre no puede llegar a su plenitud sino en y a través de la polis; en el estado de las Leyes, los asuntos humanos ya no tienen gran valor.

${ }^{21}$ Clío, la historia; Euterpe, la música; Talía, la comedia; Melpómene, la tragedia; Terpsícore, la danza; Érato, la poesía erótica y anacreóntica; Polimnia, la poesía lírica; Urania, la astronomía y Calíope, la elocuencia. 
- El importante e igualitario papel de la mujer en la educación de la República, se reduce, en las Leyes, al de puericultora.

- Se hace manifiesta la esclavitud.

- No hay división del trabajo; todos se dedican a la agricultura. La única división es que los esclavos trabajan y los ciudadanos los vigilan.

- Aunque existe el voto, se explica como obligación sólo de las dos clases más ricas de ciudadanos, no se establece como un derecho.

- En ambas obras, la virtud es el hilo conductor de su filosofía política y la educación asume un papel fundamental; apoyadas en el gobierno de un filósofo competente o bien de una legislación, lograrían la virtud de los ciudadanos. 


\section{BIBLIOGRAFÍA}

BOWEN, James, Historia de la educación occidental. El mundo antiguo. 2000 a.C.-1050 d.C. Oriente próximo y Mediterráneo, tomo I, trad. de Juan Estruch, Herder, Bacelona, 1997, 480 p.

MARROU, Henri Irénée, Historia de la educación en la antigüedad, trad. de Yago Barja de Quiroga, Sección de Obras de Educación y Pedagogía, Fondo de Cultura Económica, México, 1998, 600 p.

LARROYO, Francisco, Historia general de la pedagogía, $22^{a}$ ed., Porrúa, México, 1973, 800 p.

PLATÓN, Diálogos. [Apología, Critón, Eutifrón, Ión, Lisis, Cármenides, Hipias Menor, Hipias Mayor, Laques, Protágoras], Biblioteca Clásica Gredos, núm. 37, Gredos, Madrid, 1990, 592 p.

, Diálogos. [Fedón, Banquete, Fedro], tomo III, trad. de C. García Gual et al., Biblioteca Clásica Gredos, núm.93, Gredos, Madrid, 1988, $414 \mathrm{p}$.

Diálogos. [Parménides, Teeteto, Sofista, Político], tomo V, trad., introd. y notas de Ma. Isabel Santa Cruz, Álvaro Vallejo Campos y Néstor Luis Cordero. Biblioteca Clásica Gredos, núm.117, Gredos, Madrid, 1988, 618 p.

Diálogos. [República], tomo IV, trad. y notas de

Conrado Eggers Lan, Biblioteca Clásica Gredos, núm. 94, Gredos, Madrid, 1988, 502 p.

, Gorgias, trad. y notas de Ute Schmidt Osmanczik, Biblioteca Scriptorvm, Graecorvm et Romanorvm Mexicana, Centro de Estudios Clásicos / Instituto de Investigaciones Filológicas/UNAM, México, 1980, LXXXIII-120-CXXXII p.

Menón, trad. y notas de Ute Schmidt Osmanczik,

Bibliotheca Scriptorvm, Graecorvm et Romanorvm Mexicana, Instituto de Investigaciones Filológicas/Universidad Nacional Autónoma de México, México, 1975, XCIX-44 p. 
, Protágoras, trad., versión y notas de Ute Schmidt Osmanczik, Bibliotheca Scriptorvm Graecorvm et Romanorvm Mexicana, Coordinación de Humanidades/Universidad Nacional Autónoma de México, México, 1994, XLIX-67 p.

The Americana. A Universal Reference Library, New York, Scientific American Compiling Dep't, 1906. 
